\title{
Prevalence and risk factors of self-medication in pregnancy: A cross-sectional study from a tertiary care hospital in Eastern India
}

\author{
Mayank Gupta ${ }^{1}$, Chanchal Kumar Dalai ${ }^{2}$, Shah Newaz Ahmed ${ }^{3}$, Deblina Sarkar ${ }^{4}$, \\ Rajath Rao UR ${ }^{5}$, Santosh Kumar Nirala ${ }^{6}$ \\ ${ }^{1}$ Junior Resident, Department of General Medicine, ${ }^{2}$ Associate Professor, Department of Pharmacology, College of \\ Medicine and JNM Hospital, Kalyani, Nadia, ${ }^{3}$ Assistant Professor, Department of Pharmacology, MJN Medical College \\ and Hospital, Coochbehar, ${ }^{4}$ Assistant Professor, Department of Community Medicine, College of Medicine and JNM \\ Hospital, Kalyani, West Bengal, ${ }^{5}$ Senior Resident, ${ }^{6}$ Assistant Professor, Department of Community Medicine and \\ Family Medicine, AIIMS, Patna, Bihar, India
}

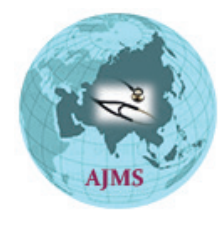

\section{A B S T R A C T}

\begin{abstract}
Background: Self-medication in pregnancy is a common but unsafe practice. There is a possibility of surreptitious exposure of the developing fetus to the teratogenic and abortifacient effects of the drugs. Aims and Objectives: In this study, we assessed the prevalence and risk factors of self-medication in pregnant mothers visiting the antenatal clinic in our hospital. Materials and Methods: A standard questionnaire seeking information on the socio-demographic profile, clinical characteristics, laboratory data, and knowledge and habits was administered to the pregnant mothers $(n=190)$. The risk factors of selfmedication were determined using Fischer's exact test. $\mathrm{P}<0.05$ was deemed statistically significant. Results: The prevalence of self-medication in pregnancy was found to be $6.3 \%$. Low education level $(P<0.027)$, employed women $(P<0.031)$, and history of miscarriage $(P<0.036)$ in the previous pregnancy were the main determinants of self-medication in the present pregnancy. Conclusion: The prevalence of self-medication in the study sample was low as compared to contemporary studies. High literacy $(94.2 \%)$ and easy availability of health facility (98\%) may be the possible reasons. Further studies are warranted to confirm the prevalence and risk factors of self-medication in this part of the country.
\end{abstract}

Key words: Low education level; Pregnancy; Prevalence; Risk factors; Self-medication

\section{Access this article online}

Website:

http://nepjol.info/index.php/AJMS DOI: 10.3126/ajms.v12i12.39217

E-ISSN: 2091-0576

P-ISSN: $2467-9100$

Copyright (c) 2021 Asian Journal of Medical Sciences

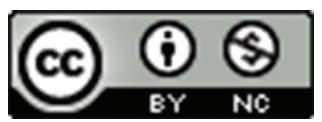

This work is licensed under a Creative Commons Attribution-NonCommercial 4.0 International License.

\section{INTRODUCTION}

Self-medication is the practice of self-administration of drugs for therapeutic purpose by individuals lacking statutory expertise for the same. The effects, whether beneficial or harmful, are unpredictable, the practice by itself is unscientific and should be discouraged. ${ }^{1}$ The implication is, however, altogether different in pregnancy where self-medication is a dangerous practice because it exposes the fetus to the teratogenic and abortifacient effects of the drugs. ${ }^{2}$ Teratogenicity refers the capacity of a drug to cause fetal abnormalities when administered to the pregnant mother. The placenta does not provide strict barrier and drugs can come to fetal circulation in greater or lesser extent and may cause harm. ${ }^{3}$ Giving birth to an abnormal child may lead to severe and lasting family and social problems. Medications prescribed during pregnancy are normally based on evaluation of their harm to the mother and fetus. In most of the cases, the first choice for treatment of a condition during pregnancy differs from treatment in nonpregnant women. Pregnant women must use the lowest therapeutic dose of medications. ${ }^{4}$ The awareness of the risk of self-medication and the prevalence of self-medication in pregnancy, therefore, assumes huge importance in maternal and child health. ${ }^{2}$ The prevalence of self-medication in this special population varies with 
respect to the geographical, social, and political conditions prevailing in the different parts of the world. ${ }^{5}$ In India, the geo-political structure is variegated across the vast country and social and cultural practices are also diverse. ${ }^{6}$ In this study, we have evaluated the prevalence and the indigenous socio-economic factors affecting self-medication in pregnant women visiting the ante-natal department of our hospital situated in a peripheral district in West Bengal.

\section{Aims and objectives}

The aims of the study were to estimate the prevalence and determine the risk factors of self-medication in pregnant mothers visiting the antenatal clinic in our hospital.

\section{MATERIALS AND METHODS}

\section{Study design}

The study was a cross-sectional, observational single center study conducted in pregnant mothers attending antenatal clinic of our institution to estimate the prevalence rate of self-medication in this special population.

\section{Ethical consideration}

The study was approved by the ethical committee of the institute. Informed consent was obtained from all patients.

\section{Sample size}

Using an expected prevalence of 15\% from previous literature, the sample size to estimate the prevalence of self-medication in our population, with $95 \%$ confidence and a precision of $5 \%$, was found to be 196 .

\section{Data collection and analysis}

The pregnant mothers who voluntarily participated and provided written informed consent were interviewed and data on self-medication, demographic, clinical characteristics, and available laboratory investigations were collected. Microsoft Excel was used for data preservation and storage. As per convention, continuous and categorical data were expressed as mean (standard deviation) and percentage/proportion, respectively. Fischer's exact test was used to study the factors associated with the practice of self-medication in the pregnant mothers. The study was conducted in November and December 2018.

\section{RESULTS}

190 pregnant mothers participated in the study. The mean age was $23.7 \pm 4.8$ years. The mean weight and height were $55.2 \pm 10.2 \mathrm{~kg}$ and $149.5 \pm 6.0 \mathrm{~cm}$, respectively. Although 179 of the 190 women were literate (Primary school-52, Middle school-4, High School-21, Senior secondary-79, Graduate-21, and Post-graduate-2), only 12 were working women; while the rest (178) were homemakers. The number of women in the different education groups and the corresponding number of self-medications is shown in Table 1.

The median monthly family income was Rs.7000 (interquartile range - 5000-10000). Data on screening for HIV and hepatitis were available for 144 of the 190 women at the time of interview. None of the women were reactive/positive for the two conditions. 68 women were anemic (Mild anemia-60 and Moderate anemia-8) but none had cyanosis or jaundice. Clubbing and bilateral pedal edema were observed in 19 and 42 women respectively. 106 women were primigravida. The number of women in the first, second, and third trimester at the time of interview was 3,56 , and 131 , respectively. 22 women had history of miscarriage. Laboratory data on hemoglobin, total leukocyte count, fasting blood sugar, post-prandial blood sugar, urea, and creatinine were available for 144, 91, 112, 92, 38, and 38 patients, respectively, and the corresponding mean (SD) values were $11.08 \pm 1.18 \mathrm{gm} \%, 7427.66 \pm 1934.9 \mathrm{cell} / \mathrm{mm}^{3}$, $91.84 \pm 7.7 \mathrm{mg} / \mathrm{dl}, 113.28 \pm 28.7 \mathrm{mg} / \mathrm{dl}, 16.98 \pm 3.3 \mathrm{mg} / \mathrm{dl}$, and $0.71 \pm 0.1 \mathrm{mg} / \mathrm{dl}$. 58 women were aware that selfmedication may have harmful effects on the fetus. 5 of them were aware that the practice poses maximum risk in the first trimester. One participant had the perception that third trimester is the most vulnerable period. The total number of women who took self-medication during the present pregnancy was 12 . Nine of them belonged to the group of women who were ignorant of the dangers of self-medication. The most common reason for taking self-medication was pain abdomen (06); one woman each took medication for fever and weakness. One woman took vitamin supplements with the belief that vitamins would improve the health of the newborn. Three women took self-medication for non-specific reasons. The medication for pain abdomen comprised of analgesics (03), antacids (02), and proton pump inhibitor (01). About 97.9\% (186) of the women were able to avail health-care facility during

\begin{tabular}{|c|c|c|c|}
\hline \multirow[t]{2}{*}{ Education } & \multicolumn{2}{|c|}{ Self-medication } & \multirow[t]{2}{*}{ Total (\%) } \\
\hline & No (\%) & Yes (\%) & \\
\hline Illiterate & $10(5.6)$ & $1(8.3)$ & $11(5.8)$ \\
\hline Primary school & $46(25.8)$ & $6(50)$ & $52(27.4)$ \\
\hline Middle school & $3(1.7)$ & $1(8.3)$ & $4(2.1)$ \\
\hline High school & $21(11.8)$ & $0(0)$ & $21(11.1)$ \\
\hline Senior secondary & 77 (43.3) & $2(16.7)$ & 79 (41.6) \\
\hline Graduate & $20(11.2)$ & $1(8.3)$ & $21(11.1)$ \\
\hline Post graduate & $1(0.6)$ & $1(8.3)$ & $2(1.1)$ \\
\hline Total & $178(100)$ & $12(100)$ & $190(100)$ \\
\hline
\end{tabular}

Values are expressed as numbers and percentages. Education up to the level of high school was taken as cutoff to dichotomize education level for association with self-medication. 
the period of their pregnancy. The mean distance of the facility from the place of residence was $15.7 \pm 13.2 \mathrm{~km}$. The factors associated with self-medication in the pregnant mothers are shown in Table 2.

\section{DISCUSSION}

In our study, though the majority of women (69.5\%) were unaware of the dangers of self-medication in pregnancy, the prevalence of self-medication in the sample was found to be only $6.3 \%$. The figure is on the lower ladder when compared to similar studies (Country, year of publication, and prevalence in percentage) - Mexico, 2018, 21.9\%; Tanzania, 2018, 46.24\% $;{ }^{8}$ Ethiopia, 2018, 15.5\% $;{ }^{9}$ Malaysia, 2020, 81.4\%; ${ }^{2}$ Ghana, 2020, 69\% $\%{ }^{10}$ France, 2020, 72\%; ${ }^{11}$ Brazil, 2020, 27.7\% $\%{ }^{12}$ Nigeria, 2012, 72.4\% $;^{13}$ and Australia, $2000,97 \% .{ }^{14}$ A meta-analysis of 13 studies conducted in 2018 estimated the overall prevalence of self-medication using the random effect model as 32\% (95\% CI, 22-44\%). ${ }^{5}$ Our study was not designed to explore the causative factors of the low prevalence of self-medication in pregnant mothers. However, we speculate that the easy availability of hospital $(98 \%)$, distance of referral hospital $<15 \mathrm{~km}$ $(71 \%)$, and high literacy $(94.2 \%)$ were the possible reasons for the lower prevalence.
About $30 \%$ of the participants were aware of the potential harm to the fetus with unsupervised medication. Majority of the women who took self-medication (75\%) belonged to the remaining part of the sample who were unaware of the dangers of self-medication. Alani et al., in an observational, cross-sectional study involving a total of 447 pregnant women found that about $82.6 \%$ of the women lacked knowledge about the risks of self-medication in pregnancy. ${ }^{2}$ The ignorance about the possible harm associated with indiscriminate use of medicines during pregnancy is one of the main reasons behind the high prevalence of self-medication in this vulnerable group. The situation is aggravated in underdeveloped societies where lack of basic health-care facilities, illiteracy, poverty, and traditional beliefs prompts the indigenous communities to seek and resort to unscientific and unsafe practices. ${ }^{13}$ While the aim of "Health for all" is an utopia which still remains to be implemented in large underprivileged geographical limits of the world, there is a simultaneous urgent necessity of inculcating habit-based safe health practices through awareness programs and public outreach. ${ }^{15}$

Studies available in the literature have identified numerous factors associated with self-medication in pregnancy. The important ones are - low income, lack of health-care facility, unaffordable medical service, illiteracy, ignorance, and easily available over the counter medicines. ${ }^{5,714}$ In our study, we

\section{Table 2: Factors associated with the practice of self-medication in pregnant women}

\begin{tabular}{|c|c|c|c|c|c|}
\hline S. No. & Factor & Factor category & Self-medication & No self-medication & $P$ value \\
\hline \multirow[t]{2}{*}{1.} & Education & Education below high school & 8 & 59 & 0.027 \\
\hline & & Education high school and above & 4 & 119 & \\
\hline \multirow[t]{2}{*}{2.} & Employment & Employed & 3 & 9 & 0.031 \\
\hline & & House wife & 9 & 169 & \\
\hline \multirow[t]{2}{*}{3.} & History of miscarriage & Yes & 4 & 18 & 0.036 \\
\hline & & No & 8 & 160 & \\
\hline 4. & Age & $\leq 24$ & 6 & 111 & 0.541 \\
\hline \multirow[t]{2}{*}{5.} & Religion & Religion 1 & 10 & 150 & 1.00 \\
\hline & & Religion 2 & 2 & 28 & \\
\hline \multirow[t]{2}{*}{6.} & Monthly income in rupees & $\leq 7000$ & 7 & 96 & 1.00 \\
\hline & & $>7000$ & 5 & 82 & \\
\hline \multirow[t]{2}{*}{7.} & Medication due to chronic illness & Yes & 2 & 20 & 0.634 \\
\hline & & No & 10 & 158 & \\
\hline 8. & Primigravida & Yes & 6 & 100 & 0.768 \\
\hline 9. & & $>2$ & 1 & 3 & \\
\hline \multirow[t]{2}{*}{10.} & History of allergy with drugs/food & Yes & 4 & 53 & 0.754 \\
\hline & & No & 8 & 125 & \\
\hline \multirow[t]{2}{*}{11.} & Knowledge of possible harm to child & Yes & 4 & 54 & 0.758 \\
\hline & due to self-medication & No & 8 & 124 & \\
\hline \multirow[t]{2}{*}{12.} & Birth of abnormal baby in previous & Yes & 2 & 5 & 0.064 \\
\hline & pregnancy & No & 10 & 173 & \\
\hline \multirow[t]{2}{*}{13.} & Distance of nearest health facility in & $\leq 16$ & 8 & 127 & 0.747 \\
\hline & Kilometers & $>16$ & 4 & 51 & \\
\hline \multirow[t]{2}{*}{14.} & Number of days of availability of & $\leq 4$ & 2 & 14 & 0.267 \\
\hline & health facility & $>4$ & 10 & 164 & \\
\hline
\end{tabular}


found that education below high school, employment, and history of miscarriage in the previous pregnancy were associated with higher chances of self-medication in pregnancy $(\mathrm{P}<0.05)$. While low education level and ignorance have also been shown to be important determinants of self-medication in pregnancy in the previous studies, the observation that employed women are more likely to resort to self-medication is being newly reported. The possible explanation is that the increased demand of work-life balance may have deprived working women in seeking proper medical advice. ${ }^{16}$ Moreover, availability of easy information over World Wide Web may have prompted some of the participants to indulge in the practice of self-medication. ${ }^{17}$

In the past two decades, information technology has penetrated even the remote corners of the Indian society. The dynamics of self-medication and the repercussions thereof are changing with the evolving scenario. A holistic surveillance to ascertain the prevalence, outcomes and the associated factors, is required to judge the true picture of the magnitude of the problem and its remedies.

\section{Limitations of the study}

Although the sample size in the study (190) was very close to the estimated sample size (196) to determine the prevalence of self-medication, the event rate of self-medication was not sufficient enough to study the causal factors using Chi-square test or logistic regression. Therefore, the possible risk factors were analyzed using Fischer's exact test. With the existing prevalence of selfmedication, a larger sample size will be required to study the determinants of self-medication in pregnancy with greater statistical confidence.

\section{CONCLUSION}

The prevalence of self-medication in the study population was $6.3 \%$. Low education level and employment were the two important determinants of self-medication in pregnancy. Further studies are required to corroborate the findings of the study.

\section{ACKNOWLEDGMENT}

The authors are grateful to the staff and faculty members of the department of Gynecology and Obstetrics, College of Medicine and JNM Hospital, for their help and cooperation in the conduct of the study.

\section{REFERENCES}

1. Ahmed SM, Sundby J, Aragaw YA and Abebe F. Self-medication and safety profile of medicines used among pregnant women in a tertiary teaching hospital in Jimma, Ethiopia: A cross-sectional study. Int J Environ Res Public Health. 2020;17(11):3993.

https://doi.org/10.3390/ijerph17113993

2. Alani AH, Hassan BA, Suhaimi AM and Mohammed AH. Use, awareness, knowledge and beliefs of medication during pregnancy in Malaysia. Osong Public Health Res Perspect. 2020;11(6):373-379.

https://doi.org/10.24171/j.phrp.2020.11.6.05

3. Benesová $\mathrm{O}$. Drug treatment in the perinatal period and the risk of functional teratogenicity. Arch Toxicol Suppl Arch Toxikol Suppl. 1996;18:89-96.

https://doi.org/10.1007/978-3-642-61105-6_10

4. Adibi JJ, Layden AJ, Birru RL, Miragaia A, Xun X, Smith MC, et al. First trimester mechanisms of gestational sac placental and foetal teratogenicity: A framework for birth cohort studies. Hum Reprod Update. 2021; (4):747-770.

https://doi.org/10.1093/humupd/dmaa063

5. Mohseni M, Azami-Aghdash S, Sheyklo SG, Moosavi A, Nakhaee M, Pournaghi-Azar F, et al. Prevalence and reasons of self-medication in pregnant women: A systematic review and meta-analysis. Int $\mathrm{J}$ Community Based Nurs Midwifery. 2018;6(4):272-284.

6. Banerji D. Social and cultural foundations of the health services systems of India. Inq J Med Care Organ Provis Financ. 1975;12(Suppl 2):70-85.

7. Alonso-Castro AJ, Ruiz-Padilla AJ, Ruiz-Noa Y, AlbaBetancourt C, Domínguez F, Ibarra-Reynoso LD, et al. Selfmedication practice in pregnant women from central Mexico. Saudi Pharm. 2018;26(6):886-890. https://doi.org/10.1016/j.jsps.2018.03.008

8. Marwa KJ, Njalika A, Ruganuza D, Katabalo D and Kamugisha E. Self-medication among pregnant women attending antenatal clinic at Makongoro health centre in Mwanza, Tanzania: A challenge to health systems. BMC Pregnancy Childbirth. 2018;18(1):16.

https://doi.org/10.1186/s12884-017-1642-8

9. Zewdie T, Azale T, Shimeka A and Lakew AM. Self-medication during pregnancy and associated factors among pregnant women in Goba town, southeast Ethiopia: A community based cross sectional study. BMC Res Notes. 2018;11(1):713.

https://doi.org/10.1186/s13104-018-3821-8

10. Gbagbo FY and Nkrumah J. Self-medication among pregnant women in two municipalities in the Central Region of Ghana. Health Care Women Int. 2021;42(4-6):547-562.

https://doi.org/10.1080/07399332.2020.1716235

11. Cabut S, Marie C, Vendittelli F and Sauvant-Rochat MP. Intended and actual use of self-medication and alternative products during pregnancy by French women. J Gynecol Obstet Hum Reprod. 2017;46(2):167-173.

https://doi.org/10.1016/j.jogoh.2016.10.005

12. Lutz BH, Miranda VI, Silveira MP, da Dal Pizzol TS, Mengue SS, da Silveira MF, et al. Medication use among pregnant women from the 2015 Pelotas (Brazil) birth cohort study. Int J Environ Res Public Health. 2020;17(3):989.

https://doi.org/10.3390/ijerph17030989

13. Abasiubong F, Bassey EA, Udobang JA, Akinbami OS, Udoh SB and Idung $\mathrm{AU}$. Self-Medication: Potential risks and hazards among pregnant women in Uyo, Nigeria. Pan Afr Med J. 2012;13:15.

14. Henry $A$ and Crowther $C$. Patterns of medication use during and prior to pregnancy: The MAP study. Aust N Z J Obstet Gynaecol. 2000;40(2):165-172.

https://doi.org/10.1111/j.1479-828X.2000.tb01140.x 
15. Musolino C, Baum F, Freeman T, Labonté R, Bodini C and Sanders D. Global health activists' lessons on building social movements for health for all. Int J Equity Health. 2020;19(1):116. https://doi.org/10.1186/s12939-020-01232-1

16. Schueller-Weidekamm $C$ and Kautzky-Willer A. Challenges of work-life balance for women physicians/mothers working in leadership positions. Gend Med. 2012;9(4):244-250.

https://doi.org/10.1016/j.genm.2012.04.002

17. Eichenberg $\mathrm{C}$ and Hübner L. [Self-medication, health and online orders: an online survey]. Gesundheitswesen. 2017;79(2):80-85.

https://doi.org/10.1055/s-0035-1549970

\section{Authors' Contributions:}

DS, MG, CKD- Concept and design of the study, prepared first draft of manuscript; SNA, DS, MG, CKD- Interpreted the results; reviewed the literature and manuscript preparation; DS, RRUR, SKN- Concept, coordination, statistical analysis and interpretation, preparation of manuscript, and revision of the manuscript.

\section{Work attributed to:}

College of Medicine and JNM Hospital, The West Bengal University of Health Sciences, Kalyani, West Bengal, India.

\section{ORCID ID:}

Dr. Mayank Gupta - id https://orcid.org/0000-0003-3796-8595

Dr. Chanchal Kumar Dalai - (1) https://orcid.org/0000-0002-5406-3440

Dr. Shah Newaz Ahmed - io https://orcid.org/0000-0003-0083-346X

Dr. Deblina Sarkar - (1) https://orcid.org/0000-0002-2294-5078

Dr. Rajath Rao UR - (1) https://orcid.org/0000-0002-7575-1162

Dr. Santosh Kumar Nirala - (1) https://orcid.org/0000-0002-2166-9470 